Journal of

Accident and

Emergency

Medicine 1995

12, 270-272

\title{
Oral and maxillofacial surgery in accident and emergency departments
}

\author{
G.D. WOOD \& K.A. LEEMING \\ Department of Oral and Maxillofacial Surgery, Arrowe Park Hospital, Merseyside, UK
}

\section{SUMMARY}

Patients with oral and facial injuries presenting as emergencies to the accident and emergency (A\&E) unit at Arrowe Park Hospital have been used to compare the treatment method of direct referral to oral and maxillofacial surgery with that of the routine A\&E procedure. A quicker and more effective treatment was administered by direct referral of patients to oral and maxillofacial surgery and an argument for such specialist staff to be based in A\&E departments is advanced.

Key words: maxillofacial surgery, oral surgery

\section{INTRODUCTION}

Most patients with oral or facial injuries presenting to accident and emergency (A\&E) departments have injuries restricted solely to the face and jaws.

It is custom and practice that the A\&E medical staff first see patients for assessment after triage and then refer them to specialist departments within the hospital when and if such expertise is required. In the case of oral or facial injuries most, if not all, are referred to departments of oral and maxillofacial surgery, if the hospital has such a service.

Time and resources could thus be wasted by the patient being seen by A\&E medical staff using the current practice.

Patients who present to A\&E departments with an oral or facial injury could be directly referred after triage to the oral and maxillofacial surgeon for treatment and A\&E staff would see only patients who require their expertise.

A study was undertaken to test this method of care for patients. The patient's outcomes were monitored by this arrangement and compared with the routine A\&E practice.

\section{METHODS}

A randomized prospective trial of clinical management was undertaken throughout December 1993 at Wirral Hospital Trust's Arrowe Park Hospital. Patients with oral or facial injuries who presented to the A\&E department were, on selected days, referred directly to the department of oral and maxillofacial surgery after triage by a nurse (B day). On the other days the standard A\&E procedure was followed, whereby after triage the A\&E staff diagnosed and referred those patients who were thought appropriate to the oral and maxillofacial surgery department (A day).

The days of the month of December, 1993, were randomly divided into $A$ and $B$ days before the start of the study. The medical and nursing staff were instructed in how the study was to be conducted and its purpose.

A form was designed to record the patient's demographic details, the time taken for assessment by the triage nurse (triage time), the time the patient was attended by medical staff (treatment time) and the time at which the patient was discharged from the A\&E department (disposal time).

The patient's injuries were classified using the International Classification of Disease 9 (ICD9). ${ }^{1}$

The radiographs taken, treatment and drugs prescribed were recorded for each patient. All completed forms were collected daily for analysis. The hospital's computer system was used to check and augment the information collected from the study and the results were compared.

\section{RESULTS}

A total of 140 patients attended the A\&E department with oral or facial injuries (63 on A days, 77 on B days) and all were included in the study.
Hospital, Upton, Wirral, Merseyside L49 5PE, UK 
Oral and maxillofacial surgery in A\&E

Table 1. Summary of study results

\begin{tabular}{|c|c|c|c|c|c|}
\hline & A day & & B day & & $P$ - value \\
\hline No. of patients & 63 & & 77 & & \\
\hline ICD9 525 & 6 & & 26 & & \\
\hline ICD9 870, 872, 873, 874 & 21 & & 18 & & \\
\hline ICD9 920 & 31 & & 33 & & \\
\hline Others & 5 & & 0 & & \\
\hline Mean (SD) triage time (min) & 6.58 & 6.7 & 6.11 & 6.5 & Not significant \\
\hline Mean (SD) disposal time (min) & 120.81 & 56.25 & 56.05 & 42.76 & $<0.001$ \\
\hline Mean (SD) no. of radiographs per patient & 3.92 & 2.2 & 3.57 & 1.53 & Not significant \\
\hline Mean (SD) treatment time from triage $(\mathrm{min})$ & 51.07 & 42.23 & 26.64 & 28.96 & $<0.001$ \\
\hline \multicolumn{6}{|l|}{ No. of general computer radiographic } \\
\hline requests & 13 & & 8 & & \\
\hline No. of patients given advice only & 6 & & 30 & & \\
\hline
\end{tabular}

There was no significant difference between the injuries (ICD9) seen and treated on A and B days (Table 1).

During the period of study the mean disposal time for all patients attending the A\&E department was $78 \mathrm{~min}$, whereas for patients with facial injuries it was $120.8 \mathrm{~min}$ on A days and $\mathbf{5 6 . 0 5} \mathrm{min}$ on $\mathrm{B}$ days. The patients treatment time was significantly reduced on $B$ days (Student's $t$-test, $P<0.001$ ).

A total of 154 radiographs on A days (average of 3.92 per patient) and 162 on B days (average of 3.57 per patient) were taken. Oral and maxillofacial staff requested fewer radiographs, but there was no significant difference between the two groups. A total of six patients had no radiographic examination or drug prescription on A days, whereas 30 on $B$ days received no such treatment. The hospital computer database confirmed 13 general radiological requests on $A$ days and eight such requests on $B$ days.

\section{DISCUSSION}

The type and complexity of cases (Table 1) were similar on A and B days and typical of those found in other studies. The results obtained are thus solely from the treatment method.

Six patients ( $4.2 \%$ of total) were seen and treated by the A\&E staff only. This study confirms, as others have previously, that patients with oral or facial injuries presenting as emergencies are principally treated by oral and maxillofacial staff when on site.

The speed of treatment of patients with oral or facial injuries (disposal time) was quicker with the method of care used on the B days. The oral and maxillofacial staff were quick to attend a patient when called on A days, but the delay for the patient before these specialists were called was considerable (mean $24.43 \mathrm{~min}$ ). The patients on A days had to be seen in a priority order with all the other emergency patients presenting to the A\&E department.

The Patient's Charter has introduced hospitalspecific performance indicators as measures of the clinical processes. ${ }^{2}$ In A\&E departments throughout the UK, triage time is used as a benchmark to compare the A\&E service offered at hospitals. There are many other standards in the Patient's Charter and it is likely that other measures will be introduced in the future to compare treatments and outcomes at different hospitals. Current performance indicators for A\&E would improve with the method of care used on B days.

Arrowe Park Hospital is totally computerized for ordering radiographs, with computer screens designed to allow the individual radiographs to be requested or a blanket 'facial views' ordered, thus leaving the choice of radiograph to the department of radiology. Most A\&E staff request 'facial views' rather than specific radiographs, which are ordered by oral and maxillofacial staff.

Radiographic examinations were fewer, appropriate to the injury and were required for treatment when requested by the oral and maxillofacial staff. Patients with oral or facially injuries would benefit from seeing an oral and maxillofacial surgeon before radiographic examination as long as doctors from this specialty are locally on hand.

It would be unrealistic to expect A\&E staff to be trained to request appropriate radiographs for the diagnosis of facial fractures because such training 
G.D. Wood \&

K.A. Leeming is core to that of the oral and maxillofacial surgeon and takes years to perfect. Computer-standard radiographic examinations clearly help to prevent over-prescription, as evident from the blanket computer-aided screens for radiographic examination.

Oral and maxillofacial staff sent significantly more patients home with advice than the A\&E staff, but with no investigation or drugs. Investigations can be the crutch of the inexperienced and uncertain doctor and this result bears out this hypothesis. Clearly there is significant over-prescription by A\&E staff in this area of patient care.

It could be argued that the patients had better quality, more appropriate and possibly cheaper treatment when seen directly by the oral and maxillofacial surgeon. In an ideal world an expert is better than a generalist and at present not every A\&E unit has on-site cover from oral and maxillofacial surgery, but as this study has demonstrated, patients can benefit from the direct use of oral and maxillofacial surgery in A\&E departments.

The triage procedure used in this study (triage nurse) before referral to the oral and maxillofacial surgery department should be supervised by a doctor and a cursory referral to the A\&E medical staff should only be necessary. Such a system will only work by a mutual trust of cross-referral between A\&E and oral and maxillofacial surgery departments.

The direct referral of patients with facial injuries to the maxillofacial surgery departments would require an increase in their staff at district general hospitals that already have the specialty. The funding for these post could be found from the monies saved from inappropriate drug and other over-prescribing, as demonstrated in this study, and may make the exercise cost-neutral.

A duty combination of on-call oral and maxillofacial staff working in A\&E departments and providing oral and maxillofacial ward cover should be further explored. Local increases in oral and maxillofacial staff could be minimal with such an arrangement and may provide another method of funding a high quality districtbased oral and maxillofácial service, while enhancing A\&E staff for the benefit of patients, even with the statutory reduction in junior doctors' hours.

\section{ACKNOWLEDGEMENTS}

Deepest thanks for all their help go to Mr J. Marrow, Consultant and Mr M. Sedgwick, senior registrar in A\&E medicine at Arrowe Park Hospital. We also thank Professor M. Edgar of the University of Liverpool for his statistical analysis.

\section{REFERENCES}

1. World Health Organisation (1990) Manual bf the International Statistical Classification of Diseases, Injuries and Cause of Death, Ninth Revision, Vol. 1, pp. 301309, 493-494, 507. WHO, Geneva.

2. Department of Health (1992) The Patient's Charter, HMSO, London.

3. Wood G.D. \& Herion S. (1991) Oral and maxillofacial surgery: should a district service be retained. Archives of Emergency Medicine 8, 257-262.

4. Rowe N.L. \& Williams J.L. (1985) Maxillofacial Injuries, Vol. 1, p. 37. Churchill Livingstone, Edinburgh. 